\title{
Orbitofrontal Cortex Volume in Area 11/13 Predicts Reward Devaluation, But Not Reversal Learning Performance, in Young and Aged Monkeys
}

\author{
Sara N. Burke, ${ }^{1,2}$ Alex Thome, ${ }^{1,2}$ Kojo Plange, ${ }^{1,2}$ James R. Engle, ${ }^{1,2}$ Theodore P. Trouard, ${ }^{4}$ Katalin M. Gothard, ${ }^{5}$ \\ and Carol A. Barnes ${ }^{1,2,3}$ \\ ${ }^{1}$ Evelyn F. McKnight Brain Institute, ${ }^{2}$ ARL Division of Neural Systems, Memory \& Aging, ${ }^{3}$ Departments of Psychology, Neurology, and Neuroscience, \\ ${ }^{4}$ Department of Biomedical Engineering, and ${ }^{5}$ Department of Physiology and College of Medicine, University of Arizona, Tucson, Arizona 85724
}

\begin{abstract}
The orbitofrontal cortex (OFC) and amygdala are both necessary for decisions based on expected outcomes. Although behavioral and imaging data suggest that these brain regions are affected by advanced age, the extent to which aging alters appetitive processes coordinated by the OFC and the amygdala is unknown. In the current experiment, young and aged bonnet macaques were trained on OFC-and amygdala-dependent tasks that test the degree to which response selection is guided by reward value and can be adapted when expected outcomes change. To assess whether the structural integrity of these regions varies with levels of performance on reward devaluation and object reversal tasks, volumes of areas 11/13 and 14 of the OFC, central/medial (CM), and basolateral (BL) nuclei of the amygdala were determined from high-resolution anatomical MRIs. With age, there were significant reductions in OFC, but not CM and BL, volume. Moreover, the aged monkeys showed impairments in the ability to associate an object with a higher value reward, and to reverse a previously learned association. Interestingly, greater OFC volume of area 11/13, but not 14, was significantly correlated with an animal's ability to anticipate the reward outcome associated with an object, and smaller BL volume was predictive of an animal's tendency to choose a higher value reward, but volume of neither region correlated with reversal learning. Together, these data indicate that OFC volume has an impact on monkeys' ability to guide choice behavior based on reward value but does not impact ability to reverse a previously learned association.
\end{abstract}

Key words: central medial nuclei; decisions making; MRI; object discrimination; reversal learning

\section{Introduction}

Cognitive processes that rely on the prefrontal cortex decline during normal aging in humans (e.g., Gazzaley et al., 2005; Resnick et al., 2007) and other animals (e.g., Lai et al., 1995; Voytko, 1999; Bizon et al., 2012). Among the functionally specialized areas of the frontal lobe (e.g., Dombrowski et al., 2001; Hornak et al., 2003; Rudebeck et al., 2008), the orbitofrontal cortex (OFC) may be more vulnerable during normative aging than other frontal areas (Resnick et al., 2007). This suggests that aged animals may have deficits on tasks that rely on the OFC before showing declines in behaviors that require other prefrontal cortical regions.

The OFC is critical for an animal's ability to update behavior based on changing reward contingencies (Gallagher et al., 1999;

\footnotetext{
Received Sept. 12, 2013; revised June 2, 2014; accepted June 6, 2014.

Author contributions: S.N.B. and C.A.B. designed research; S.N.B., K.P., T.P.T., and C.A.B. performed research; S.N.B., A.T., J.R.E., T.P.T., and K.M.G. analyzed data; S.N.B. and C.A.B. wrote the paper.

This work was supported by the McKnight Brain Research Foundation NS054465 and AG012609, state of Arizona, and Arizona Department of Health Services (ADHS). We thank Prisca Zimmerman, Julie Vogt, and Bob Vogt for lending nonhuman primate expertise; Gene Alexander and Scott Squire for imaging knowledge; and Michael Montgomery, Michelle Carroll, and Luann Snyder for help completing the manuscript.

The authors declare no competing financial interests.

Correspondence should be addressed to Dr. Carol A. Barnes, Evelyn F. McKnight Brain Institute, Life Sciences North Building, Room 355, University of Arizona, Tucson, AZ 85724. E-mail: caro@@nsma.arizona.edu.

DOI:10.1523/JNEUROSCI.3918-13.2014

Copyright $\odot 2014$ the authors $\quad 0270-6474 / 14 / 349905-12 \$ 15.00 / 0$
}

Baxter et al., 2000; Schoenbaum et al., 2002; West et al., 2011). Importantly, depending on task demands, this structure can either operate in cooperation with or in contrast to the amygdala (Murray and Wise, 2010), which is also altered by advanced age (Roesch et al., 2012). Indeed, relative to adults, elderly humans show weaker functional connectivity between the amygdala and OFC during a working memory task (Cook et al., 2007), but the task conditions examined in these studies are not those that are known to require OFC-amygdala interactions.

One type of test that specifically assesses the integrity of OFCamygdala functional connections involves reward devaluation procedures to test an animal's ability to use stimulus information to guide behaviors that optimize reward value (Málková et al., 1997). Specifically, animals that receive OFC-amygdala disconnection lesions select stimuli associated with lower value rewards more often than do control animals (Baxter et al., 2000). Importantly, this task does not rely on other prefrontal regions (Baxter et al., 2008, 2009). Thus, if changes in behavior are detected across the lifespan in the reward devaluation task, a case can be built to implicate functional changes in the OFC-amygdala circuit.

In the current experiment, young and aged bonnet macaques were tested on reward devaluation and object reversal tasks. Additionally, monkeys from both age groups were given highresolution structural MRI scans so that the boundaries of areas 
$11 / 13$ and 14 of the OFC (Carmichael and Price, 1994) and the central/medial (CM) and basolateral (BL) amygdala nuclei groups could be determined. Areas 11/13 and 14 of the OFC were analyzed separately because of documented functional differences between these subregions (Rudebeck and Murray, 2011a, b). Furthermore, the amygdala was separated into the CM and BL groups because these groups can be reliably differentiated from each other on anatomical MRI scans and show functional dissociations (Hatfield et al., 1996; Mosher et al., 2010). This enabled the extent to which changes in reward devaluation or reversal learning behaviors are associated with individual differences in the volumes of the $\mathrm{OFC}, \mathrm{BL}$, or CM regions to be tested.

\section{Materials and Methods}

Subjects. Seven young (mean age \pm SD, $9.6 \pm 0.79$ years; age range, $9-11$ years) and nine aged (mean age \pm SD, $22.8 \pm 3.3$ years; age range, $20-28$ years) female bonnet macaques (Macaca radiata) participated in a devaluation task and an object reversal task. All monkeys were born and maternally reared in a seminaturalistic environment at the State University of New York, Downstate Primate Behavior Facility. After being weaned, animals were housed in social groups of 6-12. Both young and aged monkeys had at least one viable pregnancy while at State University of New York, Downstate. Twelve monkeys (7 aged and 5 young) were moved to the University of Arizona primate facility in June, 2007 where they were paired-housed and remained in a temperature- and humiditycontrolled environment with a $12 \mathrm{~h}$ light-dark cycle. These animals participated in reward devaluation training/testing during March through May, 2008 and object reversal learning during June to October, 2008. Four additional monkeys ( 2 aged and 2 young) were moved to the University of Arizona primate facility in May, 2009 where they were housed under identical conditions to the other 12 animals. These animals participated in devaluation training/testing from June to September, 2010 and object reversal learning in April to July, 2011. All experimental procedures were performed in accordance with National Institutes of Health guidelines and were approved by Institutional Animal Care and Use Committees at the University of Arizona.

Before behavioral testing, all animals were trained to accept restraint in a primate chair and to freely move in and out of the transport box ( 50.8 $\mathrm{cm} \times 31.1 \mathrm{~cm} \times 40 \mathrm{~cm}$ ) that was used to shuttle animals between the home cage and the testing apparatus. All monkeys were given structural MRIs in July or August, 2011. Health examinations of all animals, including screenings for age-associated eye diseases, were performed semiannually, and no monkey showed any signs of vision problems.

Testing apparatuses and behavioral procedures. The behavioral apparatus and testing procedures were based on those described by Baxter et al. (2000). One difference is that only 40 object pairs were used, compared with 60 pairs in that study. Briefly, a modified Wisconsin General Test Apparatus (Harlow and Bromer, 1938) was used for all behavioral testing. The Wisconsin General Test Apparatus chamber was equipped with vertical bars situated in front of a tray for stimulus presentation. The tray included three equally spaced wells. A wooden guillotine door, controlled by the experimenter, was used to limit the animal's physical access to the wells and to impose the intertrial intervals (ITIs). A one-way mirrored screen allowed the tester to observe the animal's performance. Monkeys were habituated to the Wisconsin General Test Apparatus by first being trained to retrieve food from one of the wells. Once an animal could quickly and reliably retrieve a reward they were trained, with successive approximation, to displace an object to find and obtain food. For all monkeys, this habituation procedure took $\sim 1$ week.

Before cognitive testing began, all monkeys completed $14 \mathrm{~d}$ of food preference testing as described by Baxter et al. (2000). A combination of six of the following foods was selected for the preference testing: fruit snacks, carrots, pears, gold raisons, grapes, or dried cranberries. Before testing, the monkeys were familiar with each food. A session consisted of 30 trials with a $30 \mathrm{~s} \mathrm{ITI}$, and a trial consisted of placing two different food items in the outer wells. The monkey was allowed to view the food and then to select one. The wooden guillotine door was then lowered before the monkey could retrieve the other food item. Each of the 15 possible food pairings appeared twice in a testing session, with the left-right positions of the two foods reversed between appearances. The trials of different food pairs were pseudo-randomly presented during individual sessions and this procedure was repeated for $14 \mathrm{~d}$. The first selected food during each trial was recorded by the experimenter and the proportion of times that a monkey selected one food over another was tabulated for all 15 possible combinations for each monkey. Where pairs of foods were equally preferred by an individual monkey, one was designated food 1 and the other as food 2 . Thus, foods 1 and 2 were different for each animal to ensure that every animal's unique preferences were accounted for.

After food preference testing, the first phase of cognitive behavioral testing involved training monkeys on a set of 40 distinct object discrimination (OD) problems in which the animal was required to learn which of two objects was associated with a food reward. During each trial of OD testing, the wooden guillotine door was raised and the monkey was presented with two objects, each placed over the outer wells. The middle well was not used during OD testing. One object was arbitrarily selected to be the rewarded stimulus, whereas the other object was never associated with a food reward. The monkey was then able to displace one of the objects; and if the rewarded object was selected, the monkey was able to retrieve the food reward and then the guillotine door was lowered. If the incorrect object was selected, the wooden door was immediately lowered to prevent the animal from attempting to move the other object. There was a $20 \mathrm{~s}$ ITI between OD trials, and each pair of objects appeared in only trial per session for a total of 40 trials per day. Twenty of the rewarded objects were rewarded with food 1 , whereas the other 20 were rewarded with food 2. The rewarded object in each pair, the food reward assignment (food 1 or food 2), and the order of the objects pairs remained constant across testing sessions. Thus, there was a secondary association that a particular object was always rewarded with food 1 , whereas a different object on a separate trial was always rewarded with food 2 . The left-right position of the rewarded objects in each pair was randomized. Monkeys were trained on the OD task until a criterion performance of $90 \%$ over 5 consecutive days was reached, that is, 180 of 200 trials correct. Figure $1 A$ shows a schematic of the OD task.

After monkeys had attained criterion performance on the OD task, they participated in the devaluation task, which tests an animal's ability to use the object-food association to make choices based on the predicted value of the food reward. This involves four critical test sessions (two baseline sessions, one session of devalued food 1, and one session of devalued food 2), each performed on a separate day. In all of these sessions, only the rewarded objects were used, and all of the nonrewarded objects were set aside. Specifically, 20 object pairs were assigned such that within a pair one object was rewarded with food 1 and the other object was rewarded with food 2. The object pair assignments remained the same during all four of the critical reward devaluation sessions, and both objects were baited with the appropriate food on all trials. The left-right position of food 1 and food 2 objects varied randomly across the trials. During testing, the monkeys were allowed to choose one of the objects in each pair and to obtain that particular food reward. The unselected object-food combination was removed during the ITI before the next trial began. Thus, for this testing session, every object choice was rewarded, and it was only the type of reward (food 1 or food 2) that varied.

The first critical devaluation task test session was a baseline session, in which the monkey performed the 20 trials but was not given any food before testing (Fig. $1 B, C$, left). For the testing session on the day immediately following the first baseline test, testing was preceded by a selective satiation procedure for food 1. Paired-housed monkeys were separated for this procedure, and selective satiation consisted of putting 1 cup $(\sim 0.24 \mathrm{~L})$ of food 1 in a food box attached to the monkey's home cage. This took place $\sim 18-24 \mathrm{~h}$ after the last feeding. The monkey was allowed to eat the food without being directly observed for $15 \mathrm{~min}$. Then the experimenter entered the room and checked the amount of food eaten. If the monkey had eaten most of the food, another $1 / 4 \operatorname{cup}(\sim 0.06 \mathrm{~L})$ of food 1 was added to the food box. Whether additional food was given or not, the experimenter now observed the monkey through a window from outside the animal housing room until the monkey refrained from taking food from the food box for $5 \mathrm{~min}$. If the monkey emptied the food box again, another $1 / 4$ cup $(\sim 0.06 \mathrm{~L})$ of food 1 was added to the food box and 


\section{Reward Devaluation Procedures A Training}

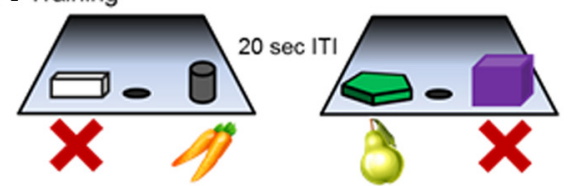

B Day 1: Baseline test 1

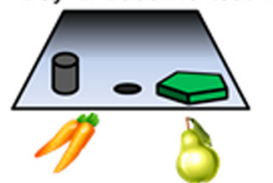

C Day 5: Baseline test 2
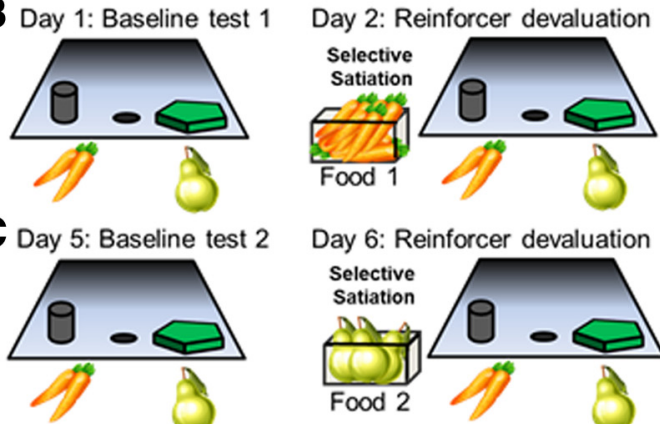

\section{Day 6: Reinforcer devaluation}

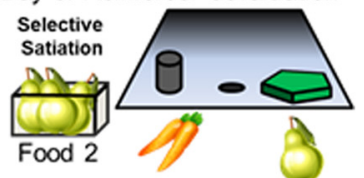

Reversal Learning Procedures

D Training to criterion

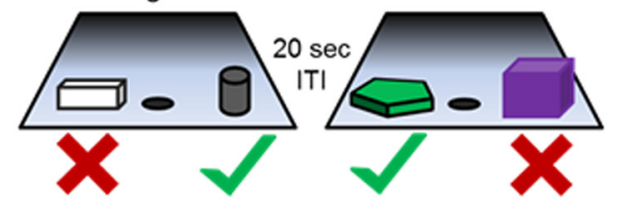

E Object Reversal

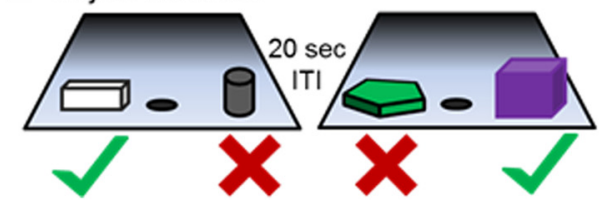

Figure 1. Schematic of reward devaluation task and reversal learning tasks. A, All monkeys were trained on an $O D$ task with 40 different object pairs in which one object was always rewarded while the other was never associated with a food reward. Twenty of the pairs were rewarded with food 1 (carrots in this example) and the other 20 pairs were rewarded with food 2 (pears in this example). The order of object pair presentation to the monkey and the food used to reward the correct response for each pair were consistent across all testing sessions. Monkeys were trained to a criterion performance of $90 \%$ correct over 5 consecutive days. After this was achieved, the monkey participated in four critical test sessions that were used to evaluate reward devaluation performance. $\boldsymbol{B}, \boldsymbol{C}$, For the four critical test sessions, only the rewarded objects from the original $\mathrm{OD}$ task were used, and the monkey performed 20 trials in which a food 1 object was paired with a food 2 object (left panels). During the Baseline Test 1 session on Day 1 ( $\boldsymbol{B}$; left), the monkey received no food before testing. On Day 2 the next day, testing was preceded by a selective satiation procedure for food 1 (carrots in this case; right panel). The 20-pair $0 \mathrm{D}$ test session began within $10 \mathrm{~min}$ of the monkey completing the satiation procedure ( $\boldsymbol{B}$; right). Two days later, the animal performed the second baseline test $(\boldsymbol{C}$; left). The day following the second baseline test, the monkey participated in another selective satiation procedure with food 2 and was again tested with food 1 and 2 objects within 10 min of completing satiation (C; right). $\boldsymbol{D}$, Reversal learning testing began with the monkeys relearning the 40 object pairs from the first OD task to a criterion of $90 \%$ correct over 5 consecutive days. $E$, Once criterion performance was achieved, the rewarded object was reversed and a correct response corresponded to the animal selecting the previously unrewarded object. Testing continued until the monkey attained a performance of $90 \%$ correct for 5 consecutive days.

observation continued, until the monkey refrained from eating for $5 \mathrm{~min}$. The 20-pair OD test session began (Fig. $1 B$, right) within 10 min of the monkey completing the satiation procedure (Baxter et al., 2000). All monkeys consumed between 1 and 2 cups of food, and there were no significant differences in the amount of food consumed during satiation between age groups $\left(t_{(16)}=0.26, p=0.80\right)$.

After the second critical reward devaluation testing session, monkeys were given at least $2 \mathrm{~d}$ of the standard 40 -object pair OD testing before another baseline test was initiated. This helped ensure that each animal had recovered from the selective satiation procedure. The day after the second baseline test, the monkey participated in another selective satiation procedure with food 2 (Fig. 1C). Again, the 20-pair OD test session began within $10 \mathrm{~min}$ of the monkey completing the satiation procedure. The effect of reward devaluation was quantified as a "difference score," which was the change in choices of object type (i.e., food 1 and food 2 objects) in the sessions preceded by selective satiation relative to the baseline sessions. The measure of reward devaluation performance used for analysis was the sum of the two differences scores from the different testing sessions.

After the completion of devaluation task testing with objects, monkeys completed an additional $4 \mathrm{~d}$ reward devaluation testing without objects. For this test, only the food was presented and monkeys did not have to use a secondary object-food association to guide behavior. This was done to control for the ability of satiation to modify food preferences in the different age groups. The $4 \mathrm{~d}$ of critical testing were identical to those described above, except that no objects were used. Thus, for the first day of baseline testing, the monkey was presented with food 1 and food 2 in the two outer wells, and the animal was able to see the food rewards and allowed to choose one. The wooden door was then closed for an ITI of $20 \mathrm{~s}$. This was repeated for 20 trials with the left-right position of the foods randomly alternating across trials. The following day, this procedure was repeated, but the monkey was selectively satiated on food 1 before testing. The animal was then given at least $2 \mathrm{~d}$ to recover from satiation, and then the baseline test was repeated. The second baseline test was conducted on the following day, where food 1 and food 2 preferences were tested after food 2 had been selectively satiated. The effect of food preference on reward devaluation was again quantified as a "difference score."

After all monkeys completed the devaluation tasks with objects and with no objects, they were given a 2-3 week break from cognitive testing. After this time, each animal was retrained on the 40 -object pair OD task. Once a monkey had returned to the criterion performance of $90 \%$ correct over 5 consecutive days (180 of 200 trials correct), they were then trained on an object reversal task in which the reversal sets were presented concurrently (Wilson and Gaffan, 2008). Specifically, the rewarded object became unrewarded, and the monkey had to learn that the previously unrewarded object was now the correct choice (Fig. 1D,E). During the retraining and object-reversal task, the type of food rewards given was not restricted and monkeys received a variety of different fruits, vegetables, and sugar-free candy for selecting the correct object. Animals performed this task until they reached a criterion performance of $90 \%$ over 5 consecutive days (i.e., 180 of 200 trials correct).

Image acquisition. Before image acquisition, each monkey was anesthetized with an intramuscular injection containing a combination of midazolam (0.15-0.2 mg/kg), ketamine (1.5-2.0 mg/kg), and DexMedetomidine $(0.007-0.01 \mathrm{mg} / \mathrm{kg})$. The doses were titrated according to the monkey's age with older animals receiving lower amounts of each drug. After an animal was sedated, it was given an intravenous catheter for fluids and intubated. After intubation, anesthesia was maintained with sevoflurane gas (2-3\%) administered with an MRI-compatible vaporizer and anesthesia machine.

MRI scans were acquired with a GE 3.0T Signa VH/I whole-body echospeed scanner (General Electric). The body RF coil was used for excitation and the commercial eight-channel head coil was used for reception. A customized stereotactic head holder was designed using Solidworks (Dassualt Systemes) and printed in an MRI-compatible polymer using an Objet Connex 350 printer (Objet). The holder incorporated mouth, orbit, and ear bars and positioned the head of the monkeys within the 8-channel receiver coil while in the "Sphinx" position. A set of 3 -plane localizer images were followed by a $3 \mathrm{D}$ inversion-recoveryprepped spoiled gradient-echo (3D-IR-SPGR) sequence used to obtain T1-weighted images of the whole brain with $0.6 \mathrm{~mm}$ isotropic resolution $\left(\mathrm{TR}=8.1 \mathrm{~ms}, \mathrm{TE}=3.3 \mathrm{~ms}, \mathrm{TI}=500 \mathrm{~ms}\right.$; flip angle $=20^{\circ}$; acquisition matrix $=256 \times 256 \times 86-100$ slices; FOV $=15.4 \mathrm{~mm} \times 15.4 \mathrm{~mm} \times$ 51.6-60 mm, scan time $=30: 12$ to 31:05 min:sec). This scan was performed twice and the resulting images were averaged. 
Image processing. 3D Slicer (www.Slicer.org/Slicer4; Pieper and Kikinis, Harvard University) was used to preprocess brain images. Each brain scan was corrected for misalignments and image artifacts (RF inhomogeneity). The manual transform function and N4ITK MRI bias correction procedure was used to prepare each brain scan for histogram equalization and gradient anisotropic diffusion filtering. An intracranial cavity (ICC) ROI was created using the label threshold function in 3D Slicer and included the entire cerebrum, cerebellum, and brainstem up to the most inferior plane that contained the cerebellum (Wisco et al., 2008). The mean ICC volume was $74,608.44 \mathrm{~mm}^{3}$ for the young monkeys and $72,029.81 \mathrm{~mm}^{3}$ for the old monkeys, which was not significantly different $\left(t_{(11)}=0.68, p=0.51\right)$. The ICC ROI was used to standardize all other ROI volumes. Specifically, the ROIs for each monkey were divided by the ICC volume of that monkey and then multiplied by the mean ICC volume of all monkeys to obtain a normalized ROI.

ROI boundaries for OFC and amygdala. Procedures for determining OFC ROI boundaries from anatomical MRI data were provided by Drs. David Amaral and Christopher Machado and were based on distinct cytoarchitectonic features of these regions (Carmichael and Price, 1994). Moreover, the OFC was divided into two subregions corresponding to Broadman's areas 11/13 and 14. This was consistent with the OFC subdivisions described by Preuss and Goldman-Rakic (1991), with the exception that Broadman's area 11 was included among the OFC rather than being grouped with granular frontal cortex (Preuss and GoldmanRakic, 1991). The OFC ROIs for areas 14 and 11/13 of the OFC were manually determined by two different experimenters blind to the monkey's age and cognitive performance on all tasks using the interactive 3D Slicer editor tool, and the ROIs for different hemispheres were determined separately. Area 14 consisted primarily of the gyrus rectus (Preuss and Goldman-Rakic, 1991). The anterior boundary of the OFC was the image section immediately posterior to the frontal pole. This tended to correspond to the most anterior section in which the olfactory tract was not separated from the orbital gyrus and both the cingulate and rostral sulci were prominent. The posterior boundary was set $1.2 \mathrm{~mm}$ anterior to the most posterior image section showing a rostral sulcus, which in most monkeys corresponded with the most anterior section in which the corpus callosum was not contiguous between the hemispheres and the most posterior section that did not contain the temporal pole. On each image, the medial border was defined as the fundus of the rostral sulcus and the lateral border was the fundus of the medial orbital sulcus, which was used to divide area 14 from 11/13. Areas $11 / 13$ consisted of the region between the medial and lateral orbital sulci (Preuss and Goldman-Rakic, 1991). The anterior border was the first coronal section in which both the cingulate and rostral sulci were prominent and the posterior border was identical to that of area 14. The OFC ROIs included the full extent of the gray matter in the areas described above and ended at the deep white matter (Carmichael and Price, 1994), and the gray/white matter boundary was the voxel in which the intensity clearly qualitatively differed. The OFC ROIs were determined separately for each hemisphere, and volume in $\mathrm{mm}^{3}$ was calculated from the experimenter derived boundaries using the label statistics quantification tool in 3D Slicer. An example of manually determined OFC boundaries is shown in Figure 2 for areas 11/13 (Fig. 2A) and 14 (Fig. 2B). Although some of the landmarks differed, these boundaries were homologous for OFC regions in voxel-based morphometry used in human studies in that the frontal pole marked the anterior boundary and the primary gray matter regions included were the rectal and orbital gyri (Convit et al., 2001).

Boundaries of the amygloid nuclei were determined separately by two experimenters, blind to age group and behavioral performance of the subjects. The 13 nuclei of the amygdala were collapsed into 2 ROIs: the CM group and the BL group. This separation is warranted by clear structural (Krettek and Price, 1978; Amaral et al., 1992; Swanson and Petrovich, 1998) and functional dissociations (Hatfield et al., 1996; Mosher et al., 2010). Specifically, the BL nuclei are important for updating reward value (Baxter and Murray, 2002; Murray and Wise, 2010), whereas the CM nuclei are involved in autonomic arousal and allocating attention to salient stimuli (Hatfield et al., 1996; Mosher et al., 2010). The position of the $\mathrm{CM}$ and $\mathrm{BL}$ groups relative to each other changes slightly from the anterior to posterior regions of the amygdale; thus, these 2 ROIs

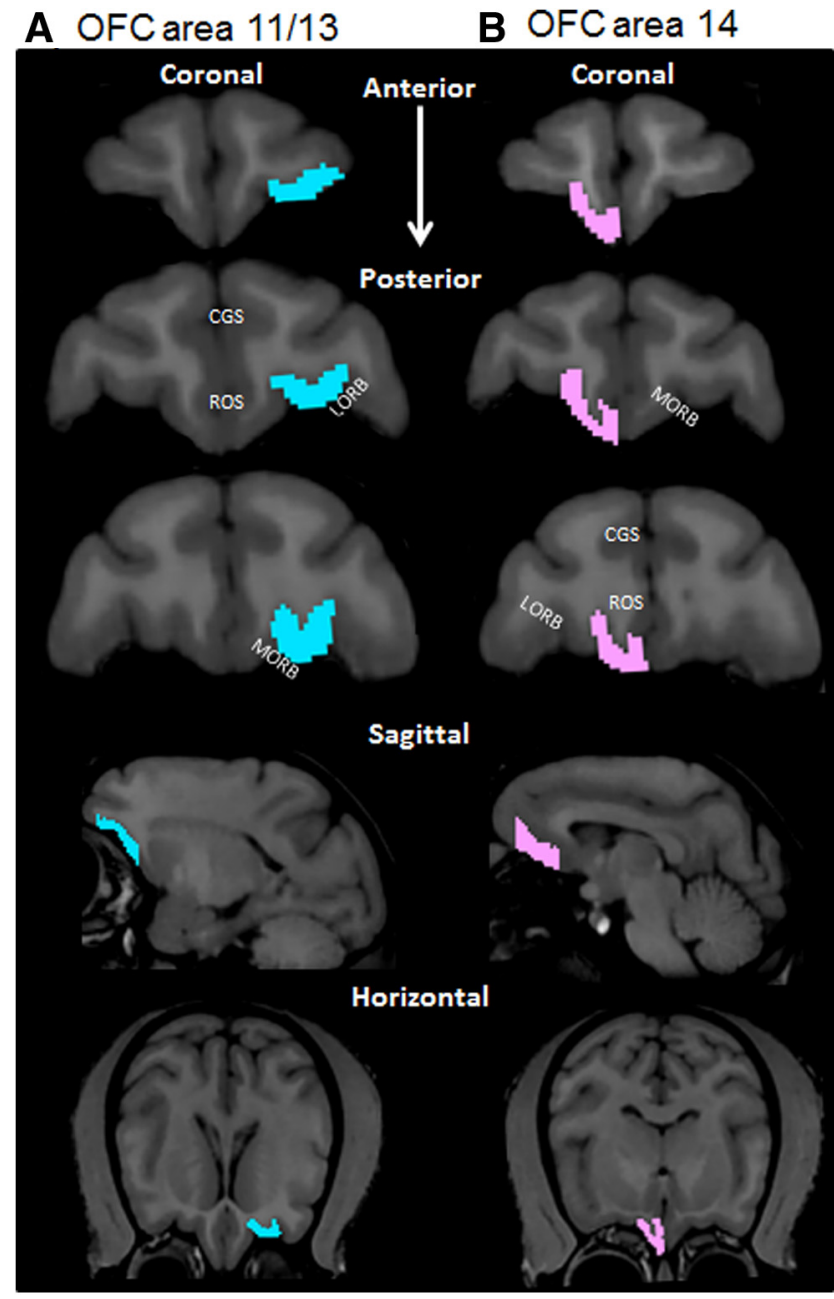

Figure 2. $\quad \mathrm{FC}$ boundaries. Representative boundaries of the $0 \mathrm{FC}$ for areas $11 / 13$ in the left hemisphere ( $\boldsymbol{A}$; blue) and 14 in the right hemisphere ( $\boldsymbol{B}$; pink) (scan view of left and right hemispheres are reversed). Two independent observers determined the $\mathrm{OFC}$ ROI according to the guidelines of Carmichael and Price (1994) and Preuss and Goldman-Rakic (1991). The top three images show representative coronal sections along the anterior to posterior axis. The fourth row of images represents a representative sagittal section; and the bottom row represents horizontal sections containing the OFC from the same monkey. CGS, Cingulate sulcus; ROS, rostral sulcus; LORB, lateral orbital sulcus; MORB, medial orbital sulcus.

were determined separately for each $0.6 \mathrm{~mm}$ coronal section. For both the $\mathrm{CM}$ and $\mathrm{BL}$ groups, the anterior borders were defined as the first MRI section where the optic nerves are merged into the optic chiasm. For the $\mathrm{BL}$ group, the posterior border was the most posterior image that did not contain the hippocampus. The CM group overlaps with the dentate gyrus of the hippocampus in one $0.6 \mathrm{~mm}$ coronal plane.

The ROI for the CM group contained the following four regions: the anterior amygdaloid area, the medial nucleus, the central nucleus, and the most ventral portion of the substantia innominata. Because some of these areas are considered "extended amygdale," they were merged into a single ROI. This was justified by their functional similarity and by the lack of visible boundaries between them. The medial boundary of the CM group was defined as the medial border of the temporal lobe. The superior border was defined as a slightly upward-curving line, which starts at the sulcus lateral of the optic chiasm and follows the inferior edge of the anterior commissure. The lateral border is marked by the white matter of the medial temporal lobe. On the most anterior and posterior sections, however, the white matter of the temporal lobe is not present. On the most anterior coronal section, the CM group is bordered by the ventral and dorsal endopyriform nuclei; whereas in the most posterior coronal section, the CM is bordered by the putamen. Because the boundary be- 
A CM group

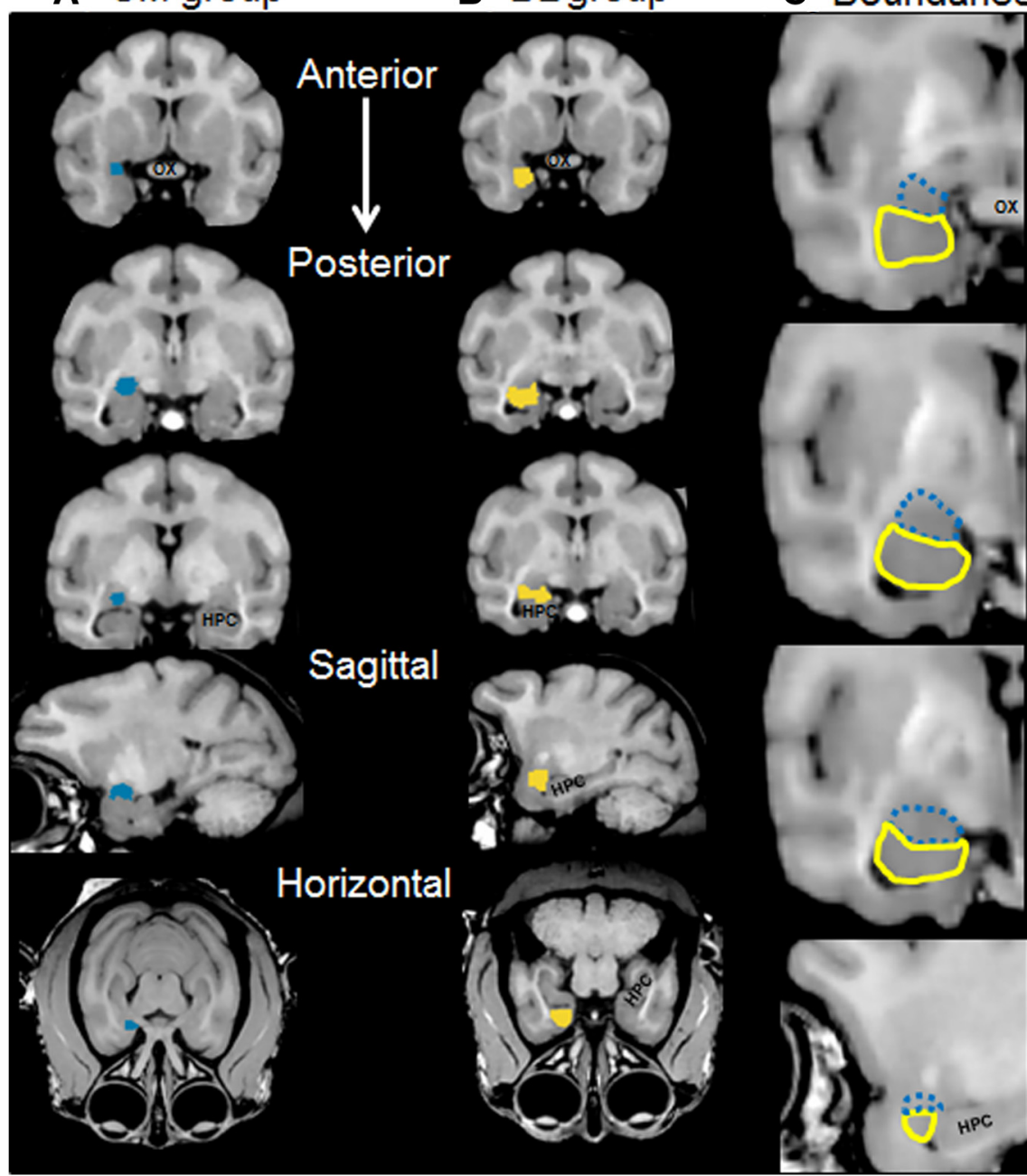

Figure 3. Amygdala nuclei boundaries. The boundaries of two groups of amygdala nuclei were determined by 2 observers. $\boldsymbol{A}$ The CM group of nuclei for the right hemisphere is shown in blue for a representative monkey in three coronal sections, and one sagittal and one horizontal section. $\boldsymbol{B}$, The BL group of nuclei for the same monkey is shown in yellow. $\boldsymbol{C}$, Representative boundary contours between the CM (blue, hashed) and BL (yellow) nuclei that were used to derive ROI volumes, in three coronal and one sagittal plane. The CM group includes areas of the extended amygdala.

tween the CM group and the endopyriform nuclei or the putamen is not visible, the lateral boundary of the CM nuclei was defined as a vertical line that ascends from fundus of the rhinal sulcus. The inferior border of the $\mathrm{CM}$ group was defined as a horizontal line originating in the center of the optic tract.

The ROI for the basolateral group contained the following eight regions: the lateral nucleus, the basal nucleus, the accessory basal nucleus, the paralaminar nucleus, the medial olfactory regions, including the cortical amygdala nuclei, amygdalopiriform transition area, and the lateral nucleus of the olfactory tract. The superior boundary of the BL group was the CM nuclei group (see above). The medial boundary was the uncal surface of the medial temporal lobe. The inferior boundary was defined by a thin white matter sheath that separates the amygdala from the deep layers of the entorhinal and perirhinal cortices. Finally, the lateral boundary is determined by the deep white matter of the medial temporal lobe. The CM and BL ROIs were determined separately for each hemisphere, and volume in $\mathrm{mm}^{3}$ was calculated from the experimenter-derived boundaries using the label statistics quantification tool in 3D Slicer. Examples of CM and BL group boundaries are shown in Figure $3 A$ and Figure $3 B$, respectively. Boundary contours used to derive ROI volumes are shown in Figure 3C.

Statistical analysis of imaging and behavioral performance. The OFC volumes obtained from the two experimenters were highly correlated $\left(r_{(24)}>0.75, p<0.0001\right.$ for all comparisons) and did not differ by $>10.6 \%$. Therefore, for all statistical comparisons, the average volumes of areas $11 / 13$ and 14 from the two experimenters was calculated and used as a single variable for each ROI. Additionally, the volumes for CM and BL ROIs were highly correlated between the two experimenters $\left(r_{(24)}>0.80, p<0.0001\right.$ for all comparisons) and did not differ by $>10.0 \%$. Thus, all statistical analyses of CM and $\mathrm{BL}$ volumes were conducted on the mean volume obtained from the two experimenters.

For correlations between ROI volume and behavioral variables, the volumes for the two hemispheres were summed to a single volume. This was justified by the lack of a significant difference in volume between the hemispheres for all 4 ROIs $\left(F_{(1,44)}=0.038, p=0.85\right.$; repeated-measures), a lack of a significant interaction effect between hemisphere and age $\left(F_{(1,44)}=0.11, p=0.75\right.$; repeated-measures $)$, and hemisphere and ROI area (areas 11/13, 14, $\mathrm{CM}$ and $\mathrm{BL}, F_{(3,44)}=0.75, p=0.53$; repeatedmeasures). Because it was hypothesized a priori that the aged monkeys would perform worse on the behavioral tasks (i.e., the experiment was a one-tail design), the $\alpha$ level for $t$ tests and ANOVAs was set to $p<0.1$. For the multiplelinear regression analyses of the relationship between ROI volume and behavioral measures, there was no prediction regarding the direction of correlations. Thus, the $\alpha$ level was set to $p<$ 0.05 . For all parameters included in the statistical models, no value met the criteria for an outlier (i.e., $>1.5$ quartiles from the lower or upper first quartiles).

\section{Results}

\section{Behavioral performance}

All 16 monkeys performed two devaluation tasks: one with objects as a secondary association of food type and a second task with no objects, just food. Figure $4 A$ shows the mean performance on these tasks for the young (dark gray) and aged (light gray) animals. The $x$-axis represents the two types of reward devaluation (with objects or no objects), and the $y$-axis is the difference score. This is a measure of the extent to which the animal's response selection was influenced by the satiation procedure, and higher values indicate better task performance. There was a main effect of objects or no objects on task performance $\left(F_{(1,14)}=33.72, p<0.0001\right.$; repeatedmeasures), such that all monkeys showed significantly higher difference scores when they did not need to use the object association to infer the food reward. Importantly, there was also a significant interaction effect of type of devaluation task and age group $\left(F_{(1,14)}=3.99, p<0.07\right)$. Post hoc analysis indicated that this interaction effect was due to the aged monkeys performing significantly worse on the reward devaluation task with objects, compared with young monkeys ( $p<0.06$; Tukey). In contrast, when the food was presented to the monkeys without objects, no significant difference was found in the degree to which reward choice was affected by previous satiation ( $p=0.40$; Tukey). These data indicate that the aged monkeys are impaired at using the secondary association between the object and the food type to guide choice behavior to maximize reward value. Importantly, 


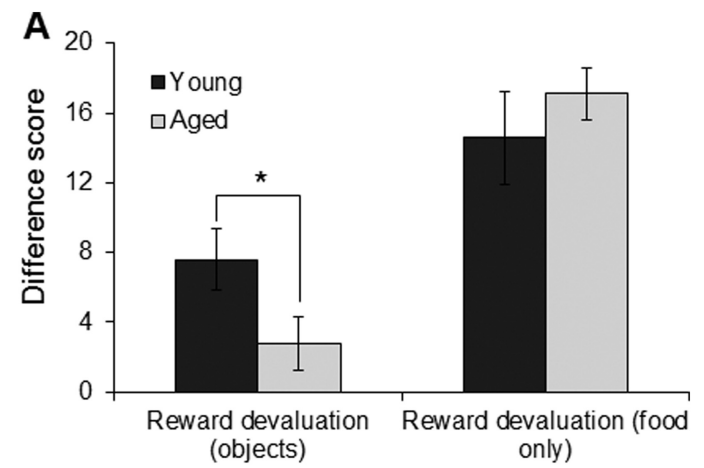

B

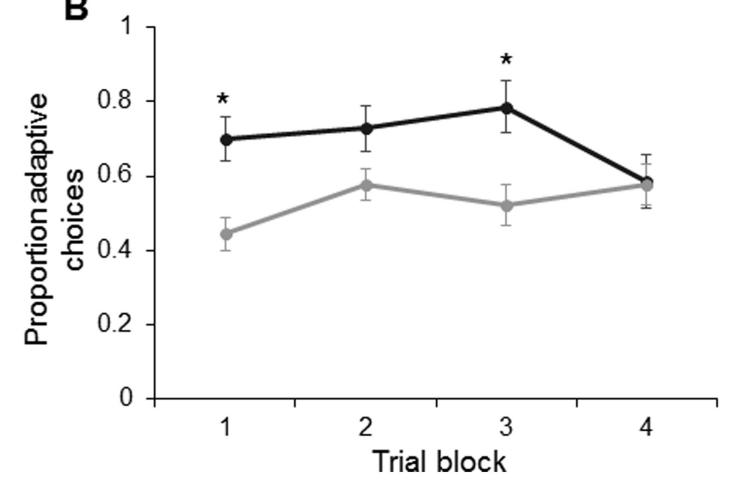

Figure 4. Reward devaluation in young and aged monkeys. $\boldsymbol{A}$, The $x$-axis represents the type of reward devaluation tested (object-associated or food only). The $y$-axis represents the mean difference score, which reflects the degree to which an animal chooses the higher valued reward (nonsatiated) over the satiated reward. There was a main effect of objects or no objects on task performance ( $p<0.0001$; repeated-measures) and a significant interaction between devaluation task type and age $(p<0.07)$. Post hoc analysis indicated that this interaction effect was the result of the aged monkeys performing significantly worse on the reward devaluation task with objects, compared with young monkeys ( $p<0.06$; Tukey). In contrast, when only the food was presented to the monkeys used, there was no significant difference in the degree to which reward choice was affected by previous satiation ( $p=0.40$; Tukey). Error bars indicate \pm SEM. $\boldsymbol{B}$, The $y$-axis represents the proportion of adaptive responses (a choice of the object not associated with the nondevalued food item) as a function of blocks of five trials $(x$-axis). Trial block did not have a significant effect on production of adaptive responses ( $p=$ 0.11 ; repeated-measures), but this did significantly vary as a function of age group ( $p<0.01)$. Error bars represent \pm 1 SEM. ${ }^{*} p<0.1$.

the performance of the monkeys on the two different reward devaluation tasks was not correlated $\left(r_{(15)}=-0.10, p=0.73\right)$, indicating that individual differences in the efficacy of the satiation procedure could not account for variability in behavioral measures on the reward devaluation task with objects. It is notable that a previous experiment measuring OFC-dependent reward devaluation in rats did not observe an effect of age on performance (Singh et al., 2011). A likely explanation for the apparent discrepancy between the current data and the work of Singh et al. (2011) is that several differences between the implementation of reward devaluation procedures in rats and monkeys may make this task considerably more cognitively demanding when used with primates and therefore more sensitive to detecting age differences. First, as used by Singh et al. (2011), the rats only had to learn a conditioned taste aversion response (sucrose pellet paired with $\mathrm{LiCl}$ administration) as opposed to the $40 \mathrm{ob}-$ ject-food pairs in the current experiment. Furthermore, in the current monkey study and in previous nonhuman primate reward devaluation investigations (Baxter et al., 2000; Izquierdo and Murray, 2010), only one of two rewards is being devalued and the animal has to selectivity choose between two relatively good options. In rats, because the learned response is not re- warded during the devaluation testing, there is no option and the animals either responds or does not. Because monkeys are given a choice between two options, the task may be cognitively challenging, compared with rodent procedures and even more strongly OFC dependent.

To determine whether learning or time since satiation procedures might be influencing choices of the objects associated with food 1 versus food 2, object selection was analyzed in serial blocks of five trials (Izquierdo and Murray, 2010). Similar to the procedures used by Izquierdo and Murray (2010), for each monkey, the 20 trial sessions that followed selective satiation were scored with a 1 to denote the choice of the object associated with the food not devalued through satiation (an adaptive choice), or with a 0 if the object associated with the devalued food was selected. Data for the two sessions that followed satiation were averaged and then collapsed into five trial blocks. Group mean scores are provided in Figure $4 B$, with higher scores indicating more adaptive choice behavior. A score of 0.5 indicates that the monkey's object selection was not influenced by the satiation procedure. A comparison of the young and aged monkeys' adaptive choices was subjected to a repeated-measures ANOVA with the withinsubject factor of trial block and the between-subjects factor of age group. Trial block did not have a significant effect on the probability of monkeys to select objects associated with the nondevalued food $\left(F_{(3,42)}=2.14, p=0.11\right.$; repeated-measures $)$. Age group, however, had a significant effect on the probability of animals making adaptive choices $\left(F_{(1,14)}=11.01, p<0.01\right)$, with the young monkeys selecting the object associated with the nonsatiated food more compared with the aged animals. The interaction between age group and trial block was also significant $\left(F_{(3,42)}=3.99, p<0.05\right.$; repeated-measures). Post hoc analysis indicated that this was due to significant differences in the probability of young and aged animals making adaptive choices on trial blocks 1 and 3 ( $p<0.02$ for both comparisons; Tukey), but not trial blocks 2 and 4 ( $p>0.4$ for both comparisons; Tukey). The difference in adaptive responses, however, did not significantly differ across trial blocks in either young $(p>0.2$ for all comparisons; Tukey) or aged ( $p>0.4$ for all comparisons; Tukey) monkeys. This indicates that learning or other factors that could vary over a testing session did not significantly influence object choice. Overall, these data support the observation that, with age, there is a reduced ability of animals to use an association between a stimulus and a reward to guide optimal choice behavior.

Before reward devaluation testing, all monkeys were initially trained on an OD problem with 40-object pairs until they reached criterion performance of $90 \%$ correct over 5 consecutive days (Fig. 5A). After devaluation testing, monkeys then performed an object reversal task in which the 40 rewarded objects became unrewarded for all subsequent testing. Thus, monkeys had to learn that the previously rewarded objects were now associated with an incorrect response and the previously unrewarded objects were rewarded. Monkeys performed the object reversal task until they reached a criterion performance of $90 \%$ correct over 5 consecutive days (Fig. 5A). One aged monkey died before completing this task and one young monkey failed to perform the task after the object reversal. The data from these animals were excluded from analysis. Figure $5 A$ shows the mean behavioral performance of young (dark) and aged (light gray) monkeys on the OD and object reversal tasks. There was a significant main effect of task (OD vs object reversal) on the number of incorrect trials to reach criterion performance $\left(F_{(1,12)}=183.32, p<0.0001\right.$; repeated-measures). Specifically, all monkeys took significantly longer to learn the object reversal relative to the initial OD. More- 


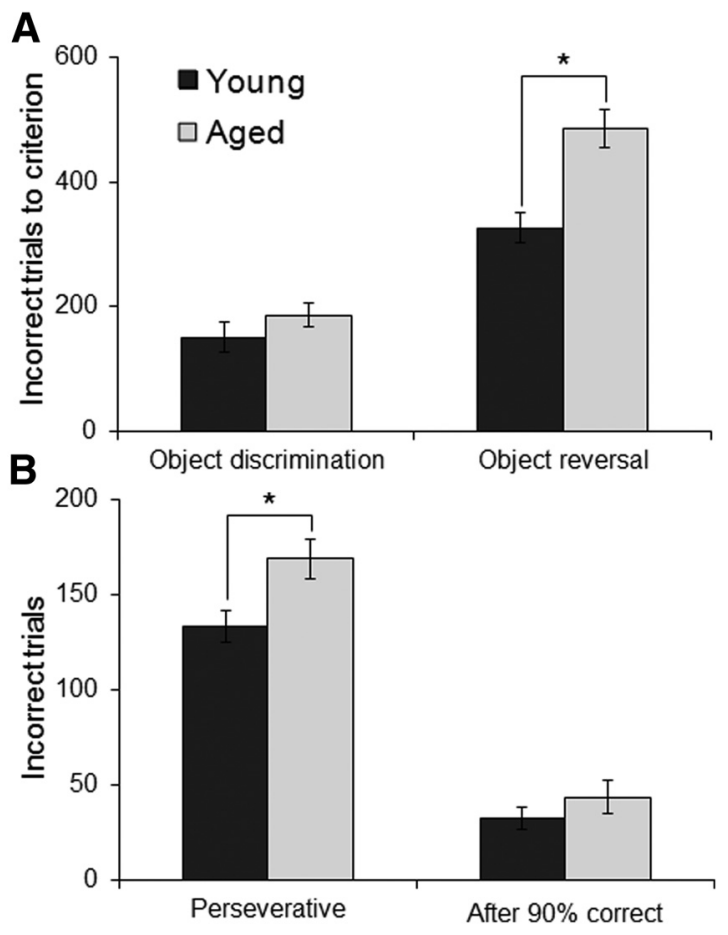

Figure 5. Behavioral performance on $0 \mathrm{D}$ and reversal learning tasks. $\boldsymbol{A}$, The performance of young (dark gray) and aged (light gray) monkeys on the initial 40-set OD task and the object reversal task. The $y$-axis represents the mean number of incorrect trials that were made before the monkeys reached the criterion performance of $90 \%$ correct for 5 consecutive days. Monkeys took significantly longer to learn the object reversal relative to the initial OD ( $p<0.0001$; repeated-measures). Moreover, there was a significant interaction of task and age group ( $p<$ 0.02 ; repeated-measures). Post hoc analysis indicated that this was the result of a significant difference in the number of incorrect trials between age groups for the object reversal ( $p<$ 0.001 ; Tukey), but not the initial OD task ( $p=0.74$; Tukey). $\boldsymbol{B}$, The mean number of perseverative errors and errors made after reaching $90 \%$ correct for the first time that young and aged monkeys made on the object reversal task. There was a significant effect of age on the number of perseverative errors $(p<0.02$ ), but not the number or errors made after reaching $90 \%$ correct $(p=0.17)$ errors. Error bars indicate \pm SEM. ${ }^{*} p<0.05$.

over, there was a significant interaction effect of task and age group $\left(F_{(1,12)}=7.50, p<0.02\right.$; repeated-measures). Post hoc analysis indicated that this was due to a significant difference in the number of incorrect trials between age groups for the object reversal ( $p<0.001$; Tukey), but not the initial OD task $(p=0.74$; Tukey). These data are consistent with previous behavioral studies showing no age deficit on OD tasks when the test objects are perceptually dissimilar (Bachevalier et al., 1991; Lai et al., 1995; Burke et al., 2011) and with studies that reported age-associated impairments on object reversal learning (Voytko, 1999).

Previous studies measuring performance on object reversals have used a single object pair, which allows for a trial-by-trial analysis of the types of errors (Rudebeck and Murray, 2008). This type of trial-by-trial analysis was not possible with the current data, as 40-object pairs were reversed. Nonetheless, it was possible to measure the amount of preservation and the degree to which monkeys benefitted from making correct choices. The number of perseverative errors made on the object reversal task was defined as the number of errors made in sessions that fell below chance performance (i.e., $<20$ correct trials). When the degree of perseveration was compared between age groups, there was a significant effect of age on number of perseverative errors $\left(t_{(12)}=2.86, p<0.02\right)$. The increase in perseverative errors could potentially be the result of the aged monkeys performing the task worse, rather than actually perseverating. This is unlikely, how- ever, as the aged monkeys performed similar to young on the initial OD task, indicating that performance is only impaired after the reversal. Although not directly tested here, it is possible that the monkeys were able to generalize the reversal rule across OD sets (Wilson and Gaffan, 2008) and that the young monkeys were more likely to use this strategy compared the aged animals. This could have also contributed to increased perseverative errors in the old monkeys.

The degree to which an animal's behavior did or did not improve following correct choices was measured as the number of incorrect trials made between the first day of testing with $90 \%$ correct and reaching criterion performance. There was no significant effect of age group on the number of errors made after the first test session with $90 \%$ correct $\left(t_{(12)}=1.45, p=0.17\right)$. Figure $5 B$ shows the mean number of perseverative and after $90 \%$ errors in the young and aged monkeys. This indicates that the behavioral performance of the different age groups benefitted from making correct choices similarly and supports the idea that the aged monkeys are not generally worse at performing OD problems but rather show increased perseverative responses following a reversal.

\section{ROI volumes in young and aged monkeys}

Previous data have shown that connections between the amygdala and the OFC are critical for normal performance on the reward devaluation task used in the current experiment (Baxter et al., 2000). This suggests that in advanced age there are functional changes within the amygdala and/or OFC that affect how these two structures interact. To investigate whether anatomical differences within these structures can partially account for devaluation task performance, anatomical MRIs were obtained from 13 of the monkeys that participated in the behavioral experiments. Figure $6 A, B$ shows the mean normalized volume of the OFC subdivisions for areas $11 / 13$ and 14 in young (dark) and aged (light gray) monkeys for the left and right hemispheres. There was no significant main effect of hemisphere for either areas $11 / 13\left(F_{(1,22)}=0.11, p=0.75\right)$ or $14\left(F_{(1,22)}=2.71, p=\right.$ $0.15)$. Age, however, had a significant effect on volume of both areas $11 / 13\left(F_{(1,22)}=6.67, p<0.02\right)$ and $14\left(F_{(1,22)}=8.68, p<\right.$ $0.001)$, but there was not a significant interaction effect between age and hemisphere for either OFC subdivision $(p>0.4$ for both comparisons). The mean normalized volume of the CM nuclei and the BL nuclei for the young (dark) and aged (light gray) monkeys are shown in Figure $6 C$ and Figure $6 D$, respectively. There was no significant main effect of hemisphere on volume in either the $\mathrm{CM}\left(F_{(1,11)}=4.01, p=0.07\right.$; repeated-measures $)$ or $\mathrm{BL}$ nuclei $\left(F_{(1,11)}=0.33, p=0.56\right.$; repeated-measures $)$. Moreover, the interaction of hemisphere and age group did not reach significance for the $\mathrm{CM}\left(F_{(1,11)}=0.00, p=0.99\right)$ or BL groups $\left(F_{(1,11)}\right.$ $=0.21, p=0.30)$. Finally, unlike the OFC, there was no significant difference in the mean normalized volume of the $\mathrm{CM}\left(F_{(1,11)}\right.$ $=0.04, p=0.84)$ or $\mathrm{BL}\left(F_{(1,11)}=0.10, p=0.75\right)$ nuclei between young and aged monkeys. Overall, these data indicate preservation of volume with age in the amygdala in both the left and the right hemispheres, but not in the OFC.

\section{ROI volume and behavioral performance}

To evaluate whether or not differences in OFC, BL, and CM volume can account for differences in the animals' behavior on the reward devaluation, OD, and object reversal tasks, the performance measures for each task were modeled using a stepwise multiple-linear regression with the four different ROIs (OFC areas 11/13 and 14, CM and BL nuclei) as independent variables in 

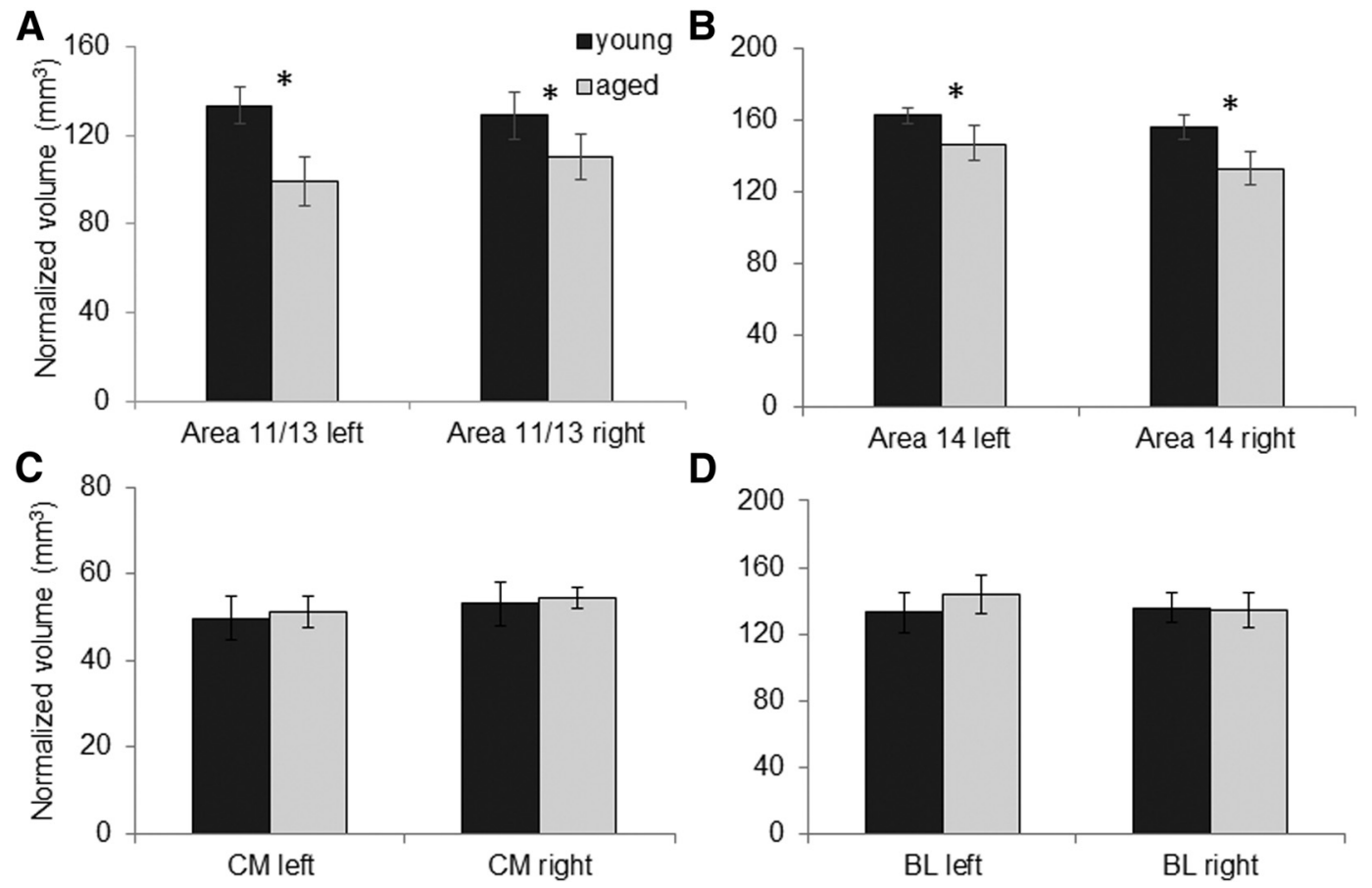

Figure 6. ROl volumes. The mean volumes $\left(\mathrm{mm}^{3}\right)$ normalized by the total intracranial cavity volume of each monkey (Wisco et al., 2008) for $(\boldsymbol{A})$ area $11 / 13$ of $0 \mathrm{OFC},(\boldsymbol{B})$ area 14 of $0 \mathrm{FC},(\boldsymbol{C}) \mathrm{CM}$ nuclei group of the amygdala, and (D) BL nuclei group of the amygdala for the left and right hemispheres in young (dark gray) and old (light gray) monkeys. Both areas 11/13 and 14 of the 0FC were significantly reduced in the aged compared with the young monkeys ( $p<0.05$ for all comparisons). There were no significant differences in mean volume of either amygdala group between young and old animals ( $p>0.7$ for all comparisons). Error bars indicate \pm SEM. ${ }^{*} p<0.05$.
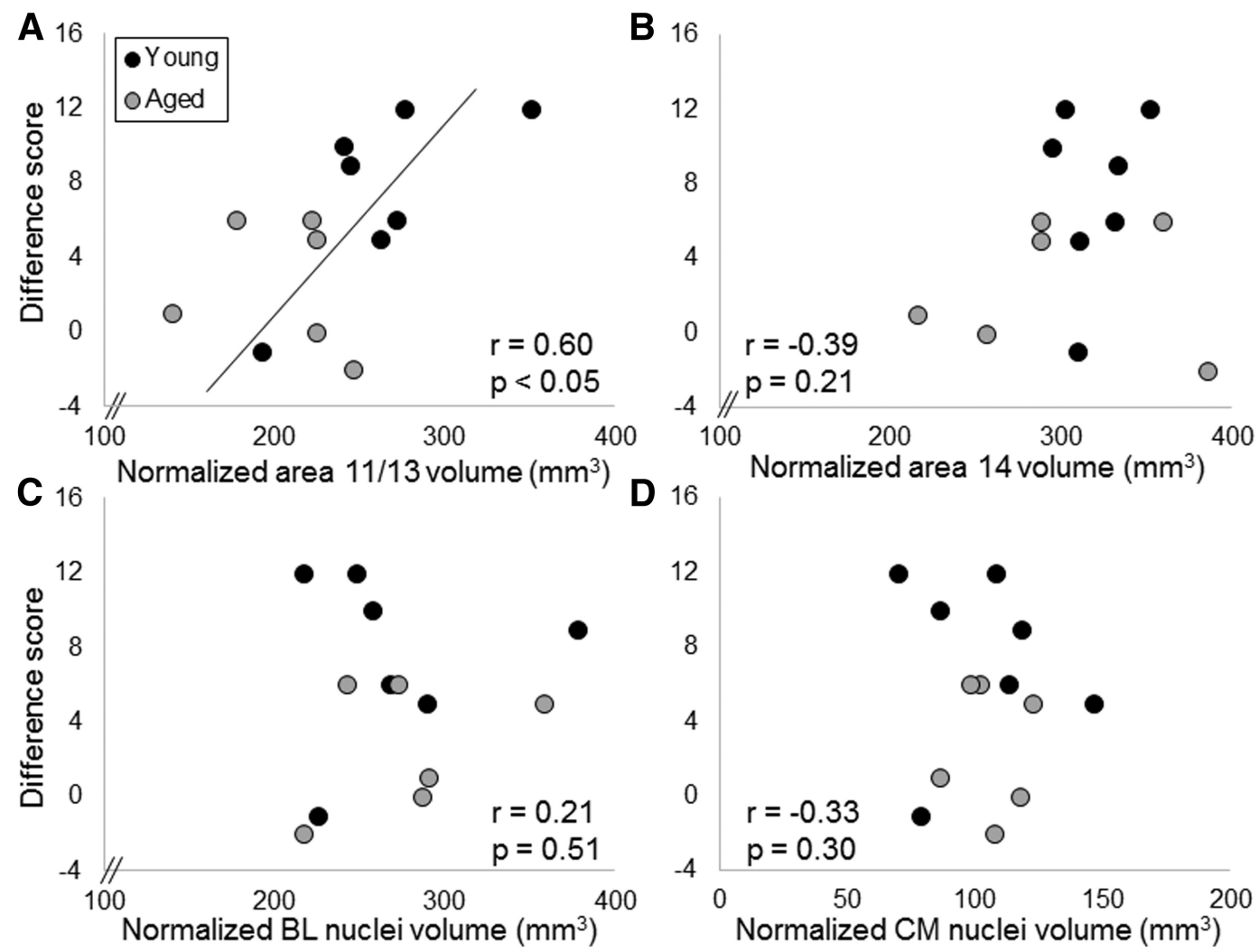

Figure 7. ROI volume and object-associated reward devaluation performance. The $y$-axes represent the summed difference scores from both testing sessions as the measures of individual performance on the reward devaluation task with objects plotted against volumes on the $x$-axes of $(\boldsymbol{A})$ area 11/13 of the OFC, $(\boldsymbol{B})$ area 14 of OFC, (C) BL nuclei of the amygdala, and $(\boldsymbol{D}) \mathrm{CM}$ nuclei of the amygdala for young monkeys (dark gray) and aged monkeys (light gray). There was a significant relationship between area 11/13 0FC volume and reward devaluation performance such that monkeys with a larger OFC showed a greater tendency to select the object associated with the higher valued reward. 

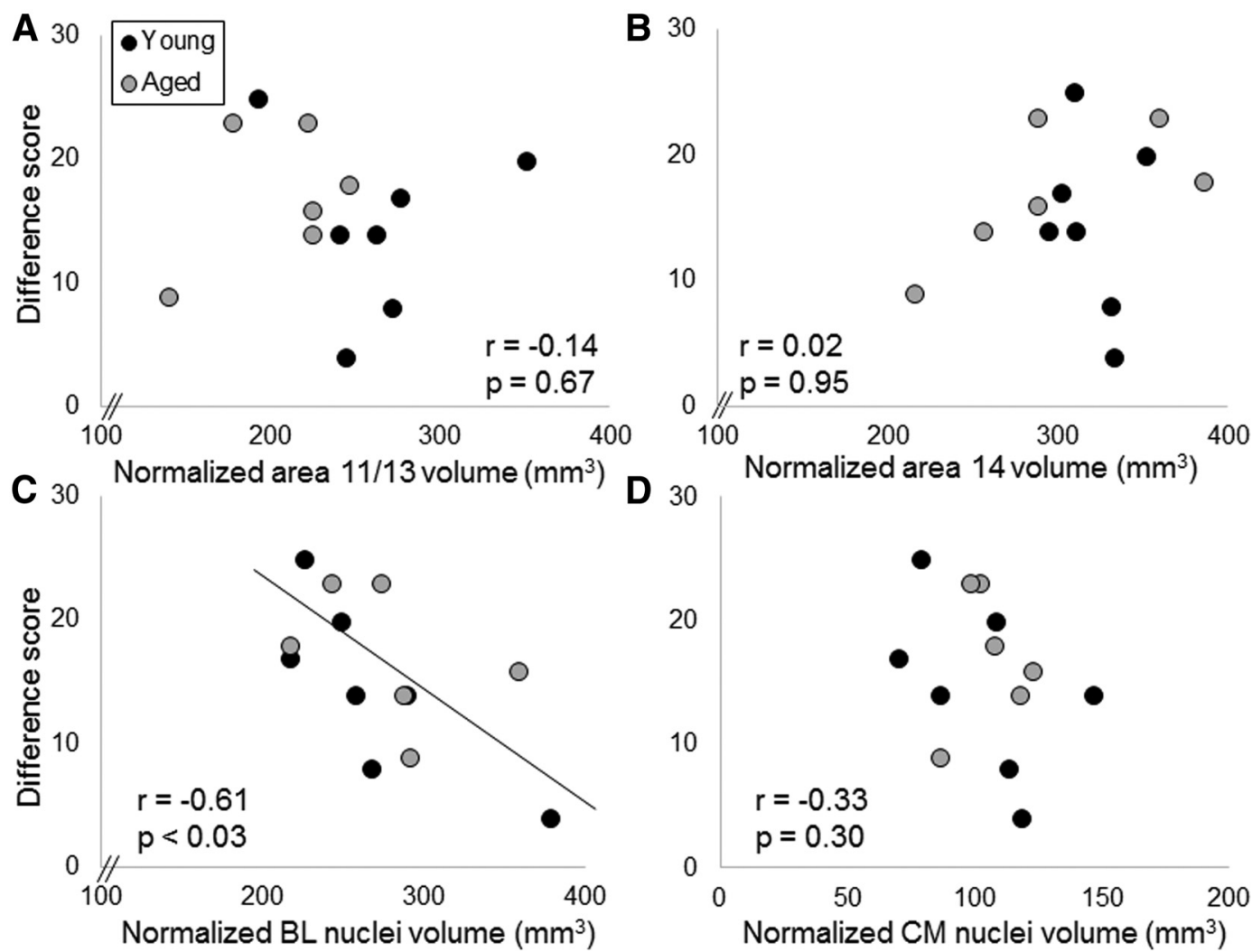

Figure 8. ROI volume and food only reward devaluation performance. The $y$-axes represent the summed difference scores from both testing sessions as the measures of individual performance on the reward devaluation task for the food only condition plotted against volumes on the $x$-axes for $(\boldsymbol{A})$ area 11/13 of the OFC, (B) area 14 of OFC, (C) BL nuclei of the amygdala, and (D) CM nuclei of the amygdala for young monkeys (dark gray) and aged monkeys (light gray). There was a significant relationship between area BL volume and reward devaluation performance such that monkeys with a smaller BL volume showed a greater tendency to select the nonsatiated, or higher valued, reward.

the model. Because there was a significant age effect on performance for the reward devaluation task with objects and the object reversal task, age at the time of testing was also entered into the model as an independent variable to account for the variance in performance that could be explained by performance differences across the lifespan.

In the 13 bonnet macaques ( 7 young, 6 aged) that received anatomical MRIs, there was a significant association between greater area 11/13 OFC volume and better devaluation task performance when objects were associated with the type of food reward $(r=0.60$, $\left.F_{(1,11)}=6.13, p<0.05\right)$. Neither area $14(r=-0.39, p=0.21)$, nor BL nuclei $(r=0.21, p=0.51)$, nor CM nuclei $(r=-0.33, p=0.30)$ volumes contributed significantly to the model. Importantly, the age of the monkey at the time of testing also did not contribute significantly to the model $(r=-0.25, p=0.44)$. This indicates that the probability of detecting a significant effect between area 11/13 volume and reward devaluation task performance was not inflated by age differences in performance. Figure 7 shows reward devaluation task performance as a function of normalized ROI volume for area 11/13 (Fig. 7A), area 14 (Fig. 7B), BL nuclei (Fig. 7C), and CM nuclei (Fig. 7D).

When the difference scores for the food-only reward devaluation task were modeled with a stepwise multiple-linear regression with the independent variables of area 11/13, area $14, \mathrm{CM}$, and BL nuclei volume, there was a significant association of smaller BL nuclei volume with greater reward devaluation for the food only $\left(r=-0.61, F_{(1,11)}=6.66, p<0.03\right)$. Neither CM nuclei $(r=0.04, p=0.91)$, nor area $11 / 13(r=-0.14, p=0.67)$, nor area $14(r=0.02, p=0.95)$ volume contributed significantly to the model (Fig. 8). Finally, age of the animal at the time of testing did not account for a significant amount of the variance in reward devaluation to a food $(r=0.40, p=0.20)$. These data indicate that, in the absence of a stimulus-reward association, animals with larger BL nuclei volume show a reduced tendency to adjust their reward choice based of the value of the reward.

Variance of the monkeys' performance on the initial 40-set OD task could not be significantly explained with the 4 ROI volumes included in the present study $(p>0.1$ for all comparisons). Likewise, the total number errors made before reaching criterion performance on the object reversal task also did not show a significant relationship with volume for any of the four ROIs examined ( $p>0.25$ for all comparisons). When the number of errors were separated based on those that were perseverative and errors in which the animals failed to benefit from a correct choice, there was also no significant relationship between perseverative errors or the number of incorrect trials after the first $90 \%$ correct with the volume of any of the 4 ROIs ( $p>0.10$ ). Scatter plots for the OFC volumes and reversal learning performance are shown in Figure 9.

\section{Discussion}

Three major novel findings have emerged from the current experiment. First, when young and old bonnet macaques performed a reward devaluation task, aged monkeys were modestly impaired at using the association between an object and a food reward to guide their choice behavior following altered reward value. These data suggest that age-related changes within the OFC disrupt the function of this structure to promote behaviors that 

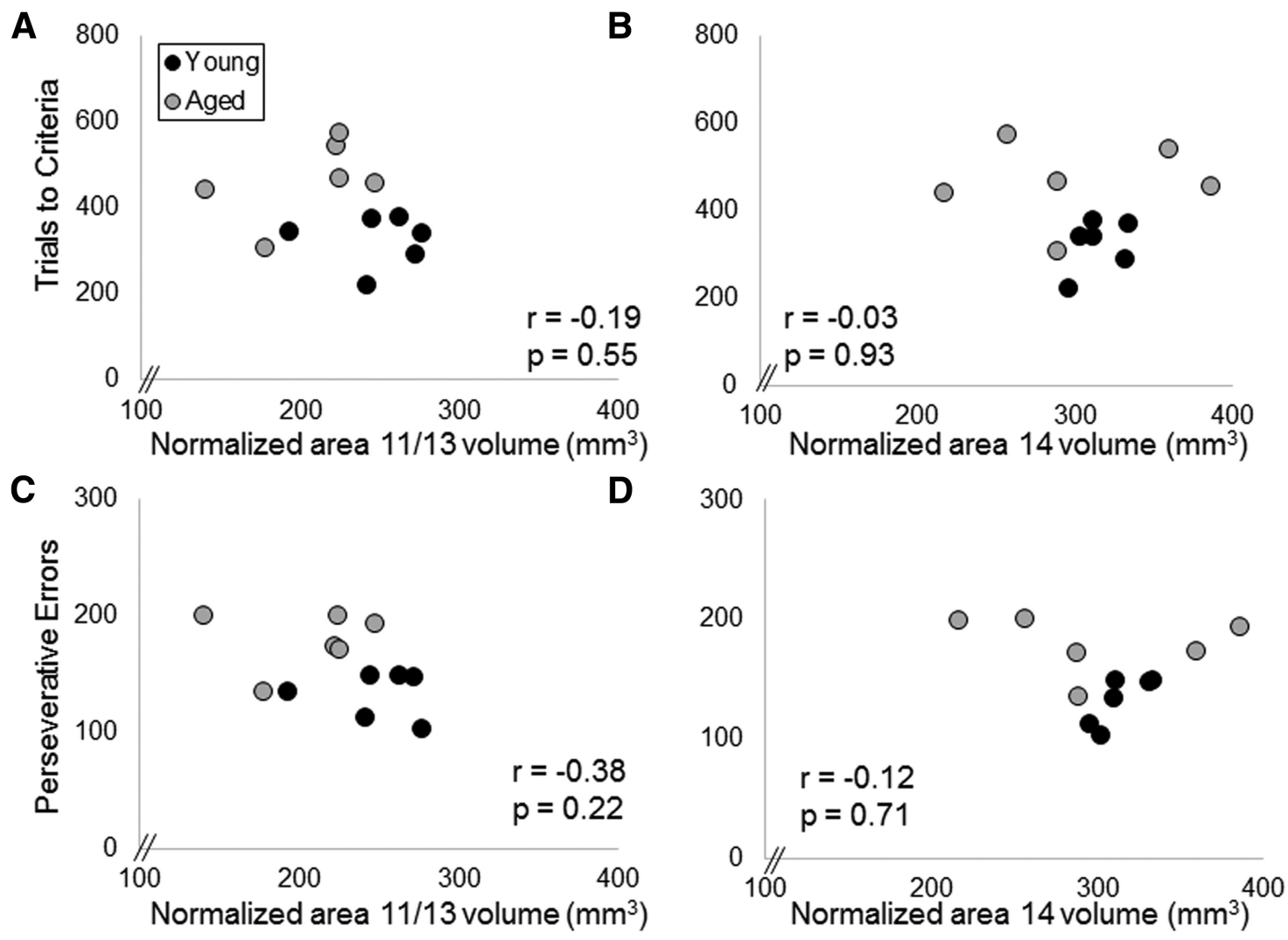

Figure 9. OFC volume and reversal learning performance. The $y$-axes represent the mean number of trials to criteria $(\boldsymbol{A}, \boldsymbol{B})$ and perseverative errors $(\boldsymbol{C}, \boldsymbol{D})$ for reversal learning area $11 / 13$ of the $\operatorname{OFC}(\boldsymbol{A}, \boldsymbol{C})$, and area 14 of OFC (B,D) for young monkeys (dark gray) and aged monkeys (light gray). There were no statistically significant relationships between the reversal learning performance measures and OFC volume for either the $11 / 13$ or area 14 subregions.

rely on the cooperation of these brain regions. Second, larger OFC gray matter volume in area $11 / 13$, but not area 14 , was predictive of an animal's tendency to choose an object associated with a higher value reward over an object associated with the devalued reward. Finally, within the amygdale, smaller BL group nuclei volume, but not CM group nuclei volume, was associated with an increased ability to optimize reward value in the absence of objects. Because OFC volume declines as a function of age, these data support the idea that this cortical region is vulnerable to the effects of normative aging processes. Moreover, these data are in line with a model of OFC-amygdala interactions in which the OFC links stimuli to outcomes (Baxter et al., 2000; Schoenbaum et al., 2011; Rudebeck et al., 2013b), and the BL updates representations of reward value (Murray and Wise, 2010).

Age effects on orbitofrontal cortical and amygdala-dependent behaviors

Aging produced a modest impairment in object-associated reward devaluation in aged compared with young monkeys. Moreover, as described in previous studies (Voytko, 1999), the aged monkeys had a significant deficit in object reversal learning that could be attributed to their increased tendency to make perseverative errors (Albert et al., 1990; Moore et al., 2003; Rhodes, 2004). Interestingly, however, area $11 / 13$ volume was associated with reward devaluation but not reversal learning performance. Together, these data support a view that aging disrupts the function of the OFC (Schoenbaum et al., 2002; Cook et al., 2007) to support reward-guided behavior (Rudebeck et al., 2013b). This is also consistent with the observed age-dependent reduction in OFC gray matter volume that was observed in this cohort of animals and has been reported for humans (Convit et al., 2001; Resnick et al., 2007; Squarzoni et al., 2012) and other primates (Alexander et al., 2008).

Lesions of the OFC have been reported to produce deficits in both stimulus-associated reward devaluation (Hatfield et al., 1996; Gallagher et al., 1999; Izquierdo et al., 2004; Machado and Bachevalier, 2007; Baxter et al., 2009) and reversal learning (e.g., Jones and Mishkin, 1972; Stalnaker et al., 2007; Rudebeck and Murray, 2008; Burke et al., 2009). Thus, it may seem paradoxical that, in this colony of bonnet macaques, area 11/13 OFC volume correlated positively with object-associated reward devaluation, but not with any measure of reversal learning. There are several potential explanations for this apparent discrepancy. First, this finding can be reconciled if the interactions of components of the OFC and amygdala are taken into consideration in terms of performance on these tasks. Specifically, disconnection lesions of the OFC and amygdala result in behaviors in which animals are more likely to select objects associated with a devalued reward, compared with control animals (Baxter et al., 2000). This suggests that these two structures act cooperatively to guide decisionmaking that optimizes reward outcomes (Baxter et al., 2000; Baxter and Murray, 2002). Also in support of this view is the recent finding that amygdala lesions result in reduced value coding of neurons in the OFC (Rudebeck et al., 2013a), which suggests that the OFC uses information about reward value from the BL nuclei to guide choice behavior that is necessary for optimal performance on a reward devaluation task. In contrast to the reward devaluation task, stimulus reversal impairments that result from OFC lesions can be ameliorated by lesions of the basolateral amygdala (Stalnaker et al., 2007). Moreover, while OFC lesions 
produce impairments in an animal's ability to benefit from a correct response after a reversal, amygdala lesions actually promote this type of learning (Rudebeck and Murray, 2008). In this view, the data presented in the current paper could indicate that animals with smaller OFC volume are less able to use reward signals from the BL to update behavior and guide decisions that optimize reward outcomes. This idea is supported by data from diffusion tensor imaging showing that the integrity of the cingulum bundle, which connects the amygdala to the frontal lobes, is compromised in old animals (Makris et al., 2007). Future imaging experiments should directly measure the integrity of this white matter tract as well as the functional connectivity between the OFC and amygdala to relate these variables to reward devaluation and OFC volume directly.

An alternative explanation for the lack of a relationship between OFC volume and object reversal learning is that the OFC is not critical for this behavior. Indeed, it has been reported that OFC-inferotemporal interactions are not critical for concurrent object reversal learning (Wilson and Gaffan, 2008). Furthermore, although it has been postulated that animals with prefrontal damage make increased perseverative errors during reversal learning due to a lack of inhibitory control (Roberts and Wallis, 2000), recent data refute that the OFC is involved in this cognitive process. Specifically, rhesus macaques with fiber-sparing excitotoxic lesions of the OFC, although impaired in reward devaluation, are not impaired on an object reversal task (Rudebeck et al., 2013b). Moreover, the previously reported loss of inhibitory control in OFC-damaged animals could be due to damage of the fiber tracts running through the posterior OFC that is caused by aspiration lesions (Rudebeck et al., 2013b). These data are consistent with the findings reported in the present paper and support a role of the OFC in value updating during reward-guided behavior. In this view, the age-related deficit in object reversal learning could be due to dysfunction in prefrontal networks outside of the OFC.

\section{The amygdala and reward value}

The amygdala is necessary for reward devaluation, but not for an animal's ability to learn a secondary association between crossmodal stimuli and a reward, when the lesion techniques spare white matter tracts that pass through this structure (Málková et al., 1997). Importantly, within the amygdale, the BL group nuclei are necessary for reward devaluation effects, whereas CM group nuclei lesions do not disrupt performance on this task (Hatfield et al., 1996; Corbit and Balleine, 2005). This is consistent with the current data that show a negative correlation between BL volume and the monkeys' tendency to select a higher valued reward, although there was no relationship between CM volume and any of the behavioral parameters measured in the current experiment. This is also supported by electrophysiological recordings from humans showing that single-unit activity in the BL is related to the perceived value of food during decision making (Jenison et al., 2011), and BL neuron activity in rat is associated with the taste and palatability of specific food rewards (Fontanini et al., 2009).

Although the current data support the view that the $\mathrm{BL}$ is involved in updating information about reward value (Baxter and Murray, 2002; Murray and Wise, 2010), it is interesting that smaller BL volume in these monkeys was associated with a greater tendency to select the higher value reward in the absence of object associations. A potential explanation for this counterintuitive relationship could be the role of the BL in impulsivity. When the monkeys were presented with two known food rewards, it is conceivable that the trials in which the devalued reward is selected are associated with more impulsive behavior. Impulsivity has been linked to increased activation of the amygdala (Kerr et al., 2014), and inactivation of the BL has been shown to increase the time needed to make choices (Hosking et al., 2014). Thus, it is possible that the monkeys with smaller BL nuclei volume made slower more deliberate choices when presented with both reward options, and this behavior increased the probability of them selecting the higher value reward.

In conclusion, the studies reported in the current manuscript support the view that the BL nuclei of the amygdala provide information regarding the current value of food rewards (Murray and Wise, 2010), whereas the OFC is critical for using stimulusreward associations to predict the value of expected outcomes (Schoenbaum et al., 2011). Under this framework, because the OFC itself does not represent value (Schoenbaum et al., 2011), interactions with the BL nuclei are critical for optimal performance on stimulus-associated reward devaluations tasks. With advanced age, there are impairments in stimulus-associated reward devaluation, which could result in reduced functional connectivity between the OFC and BL. This idea supports the finding that long-range projecting white matter tracts are particularly vulnerable to normative aging processes (Makris et al., 2007), which could have profound effects on the ability of distinct brain regions to dynamically interact to support higher-cognitive function. This suggests a productive therapeutic focus for the future regarding the development of cognitive enhancers for the elderly, maybe to target the optimization of functional interactions between different brain structures rather than facilitating the function of circuits within a single region.

\section{References}

Albert MS, Wolfe J, Lafleche G (1990) Differences in abstraction ability with age. Psychol Aging 5:94-100. CrossRef Medline

Alexander GE, Chen K, Aschenbrenner M, Merkley TL, Santerre-Lemmon LE, Shamy JL, Skaggs WE, Buonocore MH, Rapp PR, Barnes CA (2008) Age-related regional network of magnetic resonance imaging gray matter in the rhesus macaque. J Neurosci 28:2710-2718. CrossRef Medline

Amaral DG, Price JL, Pitkanen A, Carmichael ST (1992) Anatomical organization of the primate amygdaloid complex. In: The amygdala: neurobioloigcal aspects of emotion, memory, and mental dysfunction (Aggleton JP, ed), pp 1-66. New York: Wiley.

Bachevalier J, Landis LS, Walker LC, Brickson M, Mishkin M, Price DL, Cork LC (1991) Aged monkeys exhibit behavioral deficits indicative of widespread cerebral dysfunction. Neurobiol Aging 12:99-111. CrossRef Medline

Baxter MG, Murray EA (2002) The amygdala and reward. Nat Rev Neurosci 3:563-573. CrossRef Medline

Baxter MG, Parker A, Lindner CC, Izquierdo AD, Murray EA (2000) Control of response selection by reinforcer value requires interaction of amygdala and orbital prefrontal cortex. J Neurosci 20:4311-4319. Medline

Baxter MG, Gaffan D, Kyriazis DA, Mitchell AS (2008) Dorsolateral prefrontal lesions do not impair tests of scene learning and decision-making that require frontal-temporal interaction. Eur J Neurosci 28:491-499. CrossRef Medline

Baxter MG, Gaffan D, Kyriazis DA, Mitchell AS (2009) Ventrolateral prefrontal cortex is required for performance of a strategy implementation task but not reinforcer devaluation effects in rhesus monkeys. Eur J Neurosci 29:2049-2059. CrossRef Medline

Bizon JL, Foster TC, Alexander GE, Glisky EL (2012) Characterizing cognitive aging of working memory and executive function in animal models. Front Aging Neurosci 4:19. CrossRef Medline

Burke KA, Takahashi YK, Correll J, Brown PL, Schoenbaum G (2009) Orbitofrontal inactivation impairs reversal of Pavlovian learning by interfering with 'disinhibition' of responding for previously unrewarded cues. Eur J Neurosci 30:1941-1946. CrossRef Medline

Burke SN, Wallace JL, Hartzell AL, Nematollahi S, Plange K, Barnes CA (2011) Age-associated deficits in pattern separation functions of the perirhinal cortex: a cross-species consensus. Behav Neurosci 125:836847. CrossRef Medline

Carmichael ST, Price JL (1994) Architectonic subdivision of the orbital and 
medial prefrontal cortex in the macaque monkey. J Comp Neurol 346: 366-402. CrossRef Medline

Convit A, Wolf OT, de Leon MJ, Patalinjug M, Kandil E, Caraos C, Scherer A, Saint Louis LA, Cancro R (2001) Volumetric analysis of the pre-frontal regions: findings in aging and schizophrenia. Psychiatry Res 107:61-73. CrossRef Medline

Cook IA, Bookheimer SY, Mickes L, Leuchter AF, Kumar A (2007) Aging and brain activation with working memory tasks: an fMRI study of connectivity. Int J Geriatr Psychiatry 22:332-342. CrossRef Medline

Corbit LH, Balleine BW (2005) Double dissociation of basolateral and central amygdala lesions on the general and outcome-specific forms of pavlovianinstrumental transfer. J Neurosci 25:962-970. CrossRef Medline

Dombrowski SM, Hilgetag CC, Barbas H (2001) Quantitative architecture distinguishes prefrontal cortical systems in the rhesus monkey. Cereb Cortex 11:975-988. CrossRef Medline

Fontanini A, Grossman SE, Figueroa JA, Katz DB (2009) Distinct subtypes of basolateral amygdala taste neurons reflect palatability and reward. J Neurosci 29:2486-2495. CrossRef Medline

Gallagher M, McMahan RW, Schoenbaum G (1999) Orbitofrontal cortex and representation of incentive value in associative learning. J Neurosci 19:6610-6614. Medline

Gazzaley A, Cooney JW, Rissman J, D’Esposito M (2005) Top-down suppression deficit underlies working memory impairment in normal aging. Nat Neurosci 8:1298-1300. CrossRef Medline

Harlow HF, Bromer JA (1938) A test apparatus for monkeys. Psychol Rec $2: 434-436$

Hatfield T, Han JS, Conley M, Gallagher M, Holland P (1996) Neurotoxic lesions of basolateral, but not central, amygdala interfere with Pavlovian second-order conditioning and reinforcer devaluation effects. J Neurosci 16:5256-5265. Medline

Hornak J, Bramham J, Rolls ET, Morris RG, O’Doherty J, Bullock PR, Polkey CE (2003) Changes in emotion after circumscribed surgical lesions of the orbitofrontal and cingulate cortices. Brain 126:1691-1712. CrossRef Medline

Hosking JG, Cocker PJ, Winstanley CA (2014) Dissociable contributions of anterior cingulate cortex and basolateral amygdala on a rodent cost/benefit decision-making task of cognitive effort. Neuropsychopharmacology 39:1558-1567. CrossRef Medline

Izquierdo A, Murray EA (2010) Functional interaction of medial mediodorsal thalamic nucleus but not nucleus accumbens with amygdala and orbital prefrontal cortex is essential for adaptive response selection after reinforcer devaluation. J Neurosci 30:661-669. CrossRef Medline

Izquierdo A, Suda RK, Murray EA (2004) Bilateral orbital prefrontal cortex lesions in rhesus monkeys disrupt choices guided by both reward value and reward contingency. J Neurosci 24:7540-7548. CrossRef Medline

Jenison RL, Rangel A, Oya H, Kawasaki H, Howard MA (2011) Value encoding in single neurons in the human amygdala during decision making. J Neurosci 31:331-338. CrossRef Medline

Jones B, Mishkin M (1972) Limbic lesions and the problem of stimulusreinforcement associations. Exp Neurol 36:362-377. CrossRef Medline

Kerr KL, Avery JA, Barcalow JC, Moseman SE, Bodurka J, Bellgowan PS, Simmons WK (2014) Trait impulsivity is related to ventral ACC and amygdala activity during primary reward anticipation. Soc Cogn Affect Neurosci. Advance online publication. Retrieved March 13, 2014. doi: 10.1093/scan/nsu023. CrossRef Medline

Krettek JE, Price JL (1978) A description of the amygdaloid complex in the rat and cat with observations on intra-amygdaloid axonal connections. J Comp Neurol 178:255-280. CrossRef Medline

Lai ZC, Moss MB, Killiany RJ, Rosene DL, Herndon JG (1995) Executive system dysfunction in the aged monkey: spatial and object reversal learning. Neurobiol Aging 16:947-954. CrossRef Medline

Machado CJ, Bachevalier J (2007) The effects of selective amygdala, orbital frontal cortex or hippocampal formation lesions on reward assessment in nonhuman primates. Eur J Neurosci 25:2885-2904. CrossRef Medline

Makris N, Papadimitriou GM, van der Kouwe A, Kennedy DN, Hodge SM, Dale AM, Benner T, Wald LL, Wu O, Tuch DS, Caviness VS, Moore TL, Killiany RJ, Moss MB, Rosene DL (2007) Frontal connections and cognitive changes in normal aging rhesus monkeys: a DTI study. Neurobiol Aging 28:1556-1567. CrossRef Medline

Málková L, Gaffan D, Murray EA (1997) Excitotoxic lesions of the amygdala fail to produce impairment in visual learning for auditory secondary reinforcement but interfere with reinforcer devaluation effects in rhesus monkeys. J Neurosci 17:6011-6020. Medline
Moore TL, Killiany RJ, Herndon JG, Rosene DL, Moss MB (2003) Impairment in abstraction and set shifting in aged rhesus monkeys. Neurobiol Aging 24:125-134. CrossRef Medline

Mosher CP, Zimmerman PE, Gothard KM (2010) Response characteristics of basolateral and centromedial neurons in the primate amygdala. J Neurosci 30:16197-16207. CrossRef Medline

Murray EA, Wise SP (2010) Interactions between orbital prefrontal cortex and amygdala: advanced cognition, learned responses and instinctive behaviors. Curr Opin Neurobiol 20:212-220. CrossRef Medline

Preuss TM, Goldman-Rakic PS (1991) Myelo- and cytoarchitecture of the granular frontal cortex and surrounding regions in the strepsirhine primate Galago and the anthropoid primate Macaca. J Comp Neurol 310: 429-474. CrossRef Medline

Resnick SM, Lamar M, Driscoll I (2007) Vulnerability of the orbitofrontal cortex to age-associated structural and functional brain changes. Ann N Y Acad Sci 1121:562-575. CrossRef Medline

Rhodes MG (2004) Age-related differences in performance on the Wisconsin card sorting test: a meta-analytic review. Psychol Aging 19:482-494. CrossRef Medline

Roberts AC, Wallis JD (2000) Inhibitory control and affective processing in the prefrontal cortex: neuropsychological studies in the common marmoset. Cereb Cortex 10:252-262. CrossRef Medline

Roesch MR, Esber GR, Bryden DW, Cerri DH, Haney ZR, Schoenbaum G (2012) Normal aging alters learning and attention-related teaching signals in basolateral amygdala. J Neurosci 32:13137-13144. CrossRef Medline

Rudebeck PH, Murray EA (2008) Amygdala and orbitofrontal cortex lesions differentially influence choices during object reversal learning. J Neurosci 28:8338-8343. CrossRef Medline

Rudebeck PH, Murray EA (2011a) Dissociable effects of subtotal lesions within the macaque orbital prefrontal cortex on reward-guided behavior. J Neurosci 31:10569-10578. CrossRef Medline

Rudebeck PH, Murray EA (2011b) Balkanizing the primate orbitofrontal cortex: distinct subregions for comparing and contrasting values. Ann N Y Acad Sci 1239:1-13. CrossRef Medline

Rudebeck PH, Behrens TE, Kennerley SW, Baxter MG, Buckley MJ, Walton ME, Rushworth MF (2008) Frontal cortex subregions play distinct roles in choices between actions and stimuli. J Neurosci 28:13775-13785. CrossRef Medline

Rudebeck PH, Mitz AR, Chacko RV, Murray EA (2013a) Effects of amygdala lesions on reward-value coding in orbital and medial prefrontal cortex. Neuron 80:1519-1531. CrossRef Medline

Rudebeck PH, Saunders RC, Prescott AT, Chau LS, Murray EA (2013b) Prefrontal mechanisms of behavioral flexibility, emotion regulation and value updating. Nat Neurosci 16:1140-1145. CrossRef Medline

Schoenbaum G, Nugent S, Saddoris MP, Gallagher M (2002) Teaching old rats new tricks: age-related impairments in olfactory reversal learning. Neurobiol Aging 23:555-564. CrossRef Medline

Schoenbaum G, Takahashi Y, Liu TL, McDannald MA (2011) Does the orbitofrontal cortex signal value? Ann N Y Acad Sci 1239:87-99. CrossRef Medline

Singh T, Jones JL, McDannald MA, Haney RZ, Cerri DH, Schoenbaum G (2011) Normal aging does not impair orbitofrontal-dependent reinforcer devaluation effects. Front Aging Neurosci 3:4. CrossRef Medline

Squarzoni P, Tamashiro-Duran J, Souza Duran FL, Santos LC, Vallada HP, Menezes PR, Scazufca M, Filho GB, Alves TC (2012) Relationship between regional brain volumes and cognitive performance in the healthy aging: an MRI study using voxel-based morphometry. J Alzheimers Dis 31:45-58. CrossRef Medline

Stalnaker TA, Franz TM, Singh T, Schoenbaum G (2007) Basolateral amygdala lesions abolish orbitofrontal-dependent reversal impairments. Neuron 54:51-58. CrossRef Medline

Swanson LW, Petrovich GD (1998) What is the amygdala? Trends Neurosci 21:323-331. CrossRef Medline

Voytko ML (1999) Impairments in acquisition and reversals of two-choice discriminations by aged rhesus monkeys. Neurobiol Aging 20:617-627. CrossRef Medline

West EA, DesJardin JT, Gale K, Málková L (2011) Transient inactivation of orbitofrontal cortex blocks reinforcer devaluation in macaques. J Neurosci 31:15128-15135. CrossRef Medline

Wilson CR, Gaffan D (2008) Prefrontal-inferotemporal interaction is not always necessary for reversal learning. J Neurosci 28:5529-5538. CrossRef Medline

Wisco JJ, Killiany RJ, Guttmann CR, Warfield SK, Moss MB, Rosene DL (2008) An MRI study of age-related white and gray matter volume changes in the rhesus monkey. Neurobiol Aging 29:1563-1575. CrossRef Medline 